Unity Journal

Vol. III, 27-39, 2022

Doi: https://doi.org/10.3126/unityj.v3i01.43313

Prithvi Narayan Shah Research Center

Directorate General of Military Training, Nepali Army

Kathmandu, Nepal

\title{
Artificial Intelligence in Sport: An Ethical Issue
}

\section{Suman DC}

\section{Abstract}

Sport technology is the tool designed and used by human beings to achieve sporting goals and values. Induction of technology in sports has revolutionized sport equipment, training materials, and biomedical technology, which have already posed a threat to the fairness in sport (Loland, 2018). Artificial intelligence (AI) refers to a technological system which is applied to process the external data to produce knowledge or facts about that data to fulfill specific goals and tasks in a short span of time (Haenlein \& Kaplan, 2019). With the aim of fair operation of the game, administrators of modern-day sports have been adopting AI to officiate the game. However, the concept of technology is based on its instrumentality set by human beings, and ethical challenges of adopting AI in sports has greater impacts not only to the game itself but also to its participants (Loland, 2018; Watson, 2019), which itself remains a less explored area of study. To address this gap, this paper has investigated various umpiring technologies applied in modern-day cricket. For this, the study explores the concept of AI and the impacts of umpiring technology on game and stakeholders (players, officials/ administrators, and other stakeholders such as broadcasters) through the lens of several cases. Methodologically, the study reviews the academic literature about the application of technology in sports, and qualitative data have been collected through the observation of a set of relevant cases displayed in live telecast of the recent games. Furthermore, official press releases of (inter) national sport governing bodies and their reactions presented by its stakeholders through the media have been analysed to explore the impacts in a wider community regarding umpiring technology. This paper concludes with the final observation and possible resolution of the ethical issues brought forth by umpiring technology in modern-day cricket. In the wider context, this research might help us reflect the ethical considerations of applying technology in global sports.

Keywords: Technology, artificial intelligence, sport, ethics, cricket, umpiring

\section{Introduction}

Nowadays, Artificial Intelligence (AI) has been applied in almost every sector such as business, criminal justice, and national security (Mittelstadt et al., 2016). In similar ways, technology has become pervasive across every aspect of the sports. Players train, evaluate and prevent themselves from injuries by using specific technology designed for respective goals (Loland, 2018). Coaches and administrators keep, attain, and exploit the sports specific data to make a better 
decision before and during the competitions. Similarly, organizers and officials do use improvised technology to ensure fairness in every decision. In addition to this, media houses have left no stone unturned to produce the best experiences of the competitions for its viewers. Fans have been using technology to follow and remain informed with their teams' every activity.

The game of cricket has also seen a lot of technological influences in various aspects in modern days. Cricketers train by using technologies, administrators use technologies to govern and officiate the game, and fans follow their favorite players and teams by using technological platforms such as social media. Most of those technological platforms are designed to perform 'intended tasks' by using algorithms of its own kind or 'artificial intelligence' (Loland, 2018). The major concern of this paper is to reflect the implementation of umpiring technologies in cricket and the ethical issues these technologies have brought forth recently. Though the international governing body of cricket, International Cricket Council (ICC), has been implementing modern technology to officiate the game fairly (Bhattacharya, 2011; ICC, 2020b), these technologies have already posed several challenges in various aspects of the game including technological discrepancies, influences of environment, contrasting views on decision making process, technological inequality, and commercialization of sports. Likewise, such type of integration of technology has also introduced several threats to the integrity of sport in various ways, which are discussed in the fourth segment of this paper.

Methodologically, the study has explored the concept of AI and its impacts on umpiring and stakeholders (players, officials/ administrators, and other stakeholders such as broadcasters). For this, the study has reviewed the academic literature related to technology in sports, first. Then, qualitative data have been collected through the observation of a set of relevant cases displayed in live telecasts of the recent games. Furthermore, official press releases of (inter) national sport governing bodies and their reactions presented by its stakeholders through the media have been analysed to explore the impacts in a wider community regarding umpiring technology.

While exploring the concept of AI, this paper has conducted an interdisciplinary study which includes areas such as information and technology science, philosophy, and sport studies. First, this paper has applied analytic philosophy to explore the existing 'operating definition' of AI. Understanding the concept of AI has a significant role to understand the dimensions of the issue since the concept of modern-day technology is reported to be widely based on 'instrumentality' (Loland, 2018). It impacts a lot of factors including our judgement, which is one of the most important elements in terms of officiating sports.

Nevertheless, this study also acknowledges the limit of the study because of the vagueness of every concept. Hyde argues that 'vagueness is an epistemic phenomenon consisting in our ignorance of the sharp boundaries of our concepts' (Hyde, 1997). It is also known as 'cognitive phenomena of inexact knowledge.' In modern-day analytic philosophy, it is also blamed for linguistic representation of the idea or concept of the real world: the action or idea in the real world is clear but it becomes vague when we try to represent it in our words or due to lack of sharp boundaries (Hyde, 1997). However, conceptual analysis is the branch of analytic philosophy which 
helps us to identify the blurred line in a better way than before and 'adds conceptual and intellectual- historical nuance to our understanding of the interplay between these experimental developments in philosophy and literature in their different attempts to mount a more faithful representation of the real' (Zumhagen-Yekple, 2016). Selection bias is another potential concern because this study discusses the umpiring technology applied in the game of cricket only. When the game of cricket is considered, this paper means elite level or professional level men's cricket where umpiring technology has been used. It does not mean that women's or 'disabled' cricket do not use such technologies, but the application of such technologies is abundant in elite level men's cricket. Although the administrators, players, and media use various types of technologies in the game of cricket, this paper discusses application of certain umpiring technologies such as decision review system (DRS) - use of 'soft signal' and stump mics.

The following section conceptualizes AI and ethics before introducing the game of cricket, umpires, and umpiring technology in section three. Fourth section deals with the multidimensional impacts of umpiring technology, and the fifth section concludes with the final reflections.

\section{AI and ethics}

Artificial Intelligence (AI) refers to a technological system 'especially intelligent computer programs' which is applied to process the external data to produce knowledge or facts about that data to fulfill specific goals and tasks in a short span of time (McCarthy, 2004; Haenlein \& Kaplan, 2019). AI has been divided into three categories according to its usage. They are analytical, human inspired and humanized AI that represent cognitive, emotional, and social intelligence respectively. However, these categories do not come into the surface, or the users do not recognize it as a real intelligence at all when AI is in use, and this trend has been described as the AI effect. Haenlein and Kaplan (2019) also agree with the point that AI has not reached its expected state of 'intelligence' currently, which can guide, predict, and advise. The intended ideal state of AI has been described as 'Artificial General Intelligence', which is regarded as the future of AI. In terms of engineering, $\mathrm{AI}$ is not free from algorithmic bias (Rhodes \& Orlowsky, 2020). However, Haenlein and Kaplan (2019) suggest the readers analyze the current state of AI into two aspects based on what has been done till date and what the future of AI may offer.

Ethics is a branch of philosophy which explores the process of reflection in which people's decisions are shaped by their values, principles, and purposes rather than unthinking habits of social conventions. Based on this definition, 'an ethical decision is the one based on conscious reflection which gives effect to values, principles and purpose in pursuit of a proper goal.' Ethics helps us to explore the areas where morality and law fail to go. The ethicists claim that morality and law should evolve in response to the insight provided by the ethical reflections (The Ethics Center, 2020).

As AI has been conceptualized till date, the current AI might need a holistic and multidisciplinary approach to reach the expected level of 'intelligence.' When such a type of evolving AI is applied in the various sectors such as sports with the promises of 'fair play' and so on, it naturally invites unseen challenges because of the obligations 
to fulfill 'specific goals' in sports (Loland, 2018; Haenlein \& Kaplan, 2019). If the implementation of such evolving technologies is mandated in sports, a conscious reflection of its outcomes must be done ethically. Among all the ethical challenges, this essay focuses on five different ethical issues that have emerged from the implementation of umpiring technologies in the game of cricket. Such types of impacts are discussed below after providing a short background of the game of cricket and the umpiring technologies.

\section{Cricket, Umpires, and Umpiring Technology}

The game of cricket originated in the backyards of English churches and spread all around the world during the colonial era wherever the British empire went such as India, Sri Lanka, Australia, and the West Indies (Schneider \& Popp, 2020). Cricket is a team sport which 'doesn't even have rules. It has laws... cricket is one of the most complicated sports in the world...it does not even follow any apparent obvious reason' (Schneider \& Popp, 2020). The game of cricket has three official formats: the Test matches, One-Day Internationals (ODI) and Twenty20 Internationals (T20I), with the possibility of an additional Ten 10 (T10) format in Olympics (Dobell, 2021). A test match lasts for five days, with a lunch, a tea and drinks break each day. ODI cricket lasts for 6-8 hours whereas T20 lasts for approximately 3 hours (ICC, 2019b). T20 is the newest format of cricket which has attracted 'more money, fans and different style of play' from all around the world, and this development has brought the idea that cricket is 'certainly not an Englishman's game anymore' (Schneider \& Popp, 2020).
According to ICC playing conditions, there are five officials to officiate a game across all formats: two on-field umpires, a match referee, a third umpire and a fourth umpire (ICC, 2021a). Two on-field umpires are responsible to make on-field decisions related to no ball — now it has been assigned to third umpire--, wides, leg before wicket (LBW), out caught appeals, run outs, byes, leg byes, boundaries, stumping and so on. They swap their roles at the end of each over respective to their positions: square leg and bowlers' end. The third umpire is known as an offfield television umpire. Third umpire uses computer vision technologies such as slowmotion television replays, edge detection, and ball tracking to assist making final decisions on run outs, LBWs, stumpings, no balls, fair catches, boundaries. The fourth umpire is a reserve umpire if anything happens to on-field umpires or third umpire such as injuries or illness. This official also assists for pitch preparations, player injuries and replacements and replacement of match balls. The match referee is responsible for all the logistics to make sure the match runs smoothly. In addition to this, the match referee also looks after the duties such as conducting the toss before the match, liaising with teams, management, venue staff, and host staff. This person also adjudicates any breach of code of conduct by players and support staff during the match. (ICC, 2020b)

Though the international playing conditions require to appoint neutral umpires for the fair competitions, "the requirement to appoint neutral match officials will be temporarily removed from the playing conditions of all international formats. The ICC will be able to appoint locally based match officials from the Emirates ICC Elite Panel of Match Officials and the Emirates ICC International Panel of 
Match Officials' due to ongoing pandemic, and 'teams will get an additional decision review system (DRS) in each innings, increasing the number of unsuccessful appeals per innings for each team to three for Tests and two for the white-ball formats' (ICC, 2020a). 'DRS is the process under which the third umpire may be consulted in relation to a decision of the on-field umpires, either by way of an Umpire Review or a Player Review' (ICC, 2020a). Under this protocol, either on-field umpires or players including batters and fielding captains can review the decisions made by on-field umpires such as LBW.

The reason behind providing additional DRS is 'to support the less experienced umpires that may be officiating more often during this interim period. Teams will now get three unsuccessful decisions per innings per side in Tests and two unsuccessful decisions per side in ODIs and T20Is' (ICC, 2020a). For the third umpiring technology, the home cricketing board coordinates with broadcasting to set out camera specifications to capture the best angles for the third umpire. While performing jurisdiction, third umpire uses various technologies in need such as camera images, video replays, ball tracking technology, sound-based edge detection technology and stump microphone technology for the fair operation of the game (ICC, 2021a).

However, the evolving nature of AI, which has not reached the state of 'Artificial General Intelligence' yet (Haenlein \& Kaplan, 2019), naturally expected to invite several ethical issues when it is implemented in any sector including officiating sports such as cricket. Five of the main ethical issues of applying umpiring technology are analyzed in the section below.

\section{Ethical considerations of umpiring technology in cricket}

Historically, the first official third umpire was appointed in 1992 to officiate the Test match between India and South Africa. At that time, the third umpire was consulted only for run-outs, stumping and boundaries (Bhattacharya, 2011). Since then, the roles of third umpire have been expanding including assisting on-field umpires in making various decisions such as no-ball decisions that have been brought into play recently (ICC, 2021a). However, the process of using third umpiring technology has several ethical issues in modern day cricket though these upgraded technologies have been implemented for the fairer execution and better experiences of the game. The following subsections reflect the current usage of umpiring technologies in cricket.

\section{Fundamental discrepancies of umpiring technology}

Third umpires in the game of cricket use AI when on-field umpires refer to them when a situation on-field is not conclusive to decide about an action such as a catch (ICC, 2021a). When the on-field umpires are not sure whether it is a fair catch or a 'Bump Ball', they refer it to the third umpire. But the problem with the video analysis is that 'the world is composed of three-dimensional objects, but the inputs to the human eye and computers' TV cameras are two dimensional' (McCarthy, 2004). So, fundamentally, video technology has a discrepancy. This type of fundamental discrepancy has been supported by the experiments conducted by Channel 9 of Australia and Channel 4 from the UK (Selvey, 2007). In the recently concluded ICC T20 World Cup 2021, one of the controversial catching incidents occurred when India and 
Afghanistan were playing a match. One of the Indian fielders, Ravindra Jadeja appeared to take an extra ordinary running and diving catch, but it was controversially adjudged not out by the third umpire when it was referred to third umpire by the on-field umpire (Wisden, 2021). However, this is just an example of such type of incidents in terms of fair catch or 'Bump Ball.'

Likewise, 'Ultra-edge' technology — which is the product of Hawk-Eye Innovation-has been used as a part of DRS in cricket since its approval from ICC in 2015 (McGlashan, 2015). This technology is especially applied to find out whether the batter has edged the ball or not. It explores the edge 'by syncing up vision from ultra motion cameras and audio from the stump mics to deliver the most accurate and cost-effective system for detecting whether a batsman has edged the ball' (Hawk-Eye Innovation, 2015). However, the reliability of ultra-edge technology has been doubted by many. The ultra-edge seems to work based on two elements: visuals from the camera and audio from the micro-phone. First, the research shows that the camera angles are not effective to find out whether the batter has edged the ball or not because cameras cannot mirror the real action (McCarthy, 2004; Selvey, 2007). Secondly, the audio from the stump mics does create spikes in ultra-edge detection even when the batter's make the movement in the crease. For example, if the batter's bat brushes the pad or pitch, the ultra-edge displays the spikes on the screen, which creates difficulties for the third umpire to make decisions about the edge in cricket. During a Test match between Bangladesh and Pakistan played in Chattogram from 26 to 30 November 2021, Bangladeshi batter, Mushfiqur Rahim, was given caught-behind the wicket by the on-field umpire, but Rahim used DRS against that 'out' decision. However, the third umpire upheld the onfield umpire's decision. Rahim shook 'his head while walking off, perhaps he thinks the sound was off the bottom of the bat brushing his pad' (ESPNCricinfo, 2021). Though ultra-edge 'is able to differentiate more clearly over sounds created by bat, pads or clothing', the ICC General Manager said, 'we are still judging a sound and it will need interpretation as to what created that sound' (McGlashan, 2015). This statement also surfaces the issues related to the applications of ultra-edge technology in cricket.

The use of umpiring technology in the current state does not have a 'perfect' state which brings several fundamental and ethical issues that emerge from such loopholes (McCarthy, 2004: Selvey, 2007; Haenlein \& Kaplan, 2019; Rhodes \& Orlowsky, 2020). A player or a support personnel may show dissatisfaction about such type decisions directly or indirectly, but such type of act is regulated under ICC's Code of Conduct in which player or support personnel may face sanctions for 'disobeying an Umpire's instruction during an International Match' under article 2.4 which 'includes any repeated failure to comply with the instruction or directive of an Umpire during an International Match' (ICC, 2019a). From this, it can be inferred that players and support personnel are forced to follow the ICC's rules and regulations despite fundamental discrepancies of umpiring technology. ICC and its stakeholders need to do a proper reflection of such incidents.

\section{Leg before wicket ( $L B W)$, ball tracking and umpire's call}

LBW is one of the ways to get a batter out. If the batter misses and gets the ball on any 
part of the body by a fair and in-line ball which is directed towards the stump by the bowler, a batter will get out under LBW conditions (ICC, 2021a). However, it is one of the most complicated aspects in cricket in which even the cricket pundits fail to have a common ground. Even the on-field umpires, third umpire and on-field players do not have a common ground. This section discusses a couple issues of decision-making processes of umpiring technology in cricket: ball tracking and umpire's call.

To begin with, the environment such as weather, pitch conditions and air flow affect the swing and the turn of the ball in the game of cricket. However, third umpires take help of the same kind of technologies such as ball tracking technology to identify the direction of the ball in every environment. 'But technology is not flawless when it comes to calculating the bounce and movement. It's always a projection. And the actual path varies depending on the wicket and the conditions. So, the projection need not be 100 percent accurate. So, when the margins are thin, the third umpires prefer to go with the on-field umpires' call. Which is not fair.' (Krishna, 2021)

The cricket pitches in the Indian subcontinent and England or in South Africa and New Zealand are totally different where the cricket ball's swing, speed, turn, and bounce are utterly variable. For instance, 'Dynamic and unpredictable nature of ball appearance, movement and continuously changing background make the detection and tracking processes challenging' (Kamble et al., 2019). One of the controversial LBW decisions came out during ICC World Cup 2011 in the semi-final match between Pakistan and India. During the match, an Indian batter Sachin Tendulkar was given out (LBW) off the Pakistani bowler Saeed Ajmal. Tendulkar took the Players' Review, and the third umpire overturned the umpire's original decision after using the ball tracking technology known as Hawk-Eye. This incident attracted attention from various stakeholders in the cricketing world. Because of this, the technology company, Hawk-Eye Innovation, had to provide a clarification about its ball tracking technology, and it has concluded that 'the ICC were happy with the outcome of this review.' (Hawk-Eye Innovation, 2011)

Similarly, the 'umpire's call' decision regarding LBW is 'too confusing' (Tendulkar, 2020). 'Umpire's Call is the concept within the DRS under which the on-field decision of the bowler's end umpire shall stand, which shall apply under the specific circumstances ..., where the ball-tracking technology indicates a marginal decision in respect of either the Impact Zone or the Wicket Zone' (ICC, 2020). Impact Zone refers to the ball pitching line between two sets of stumps that are divided into three parts: outside off stump, in line and outside of leg stump. Wicket Zone means the area of a set of three stumps such as off, leg, top, and base of the stumps. (ICC, 2021a)

The impact and wicket zones play a significant role in LBW decisions while applying DRS, but the rules of treating of these zones between player's review and umpire's review have a huge inconsistency that makes it 'confusing' for everyone including players because 'the same ball could either be Out or Not out depending on the on-field umpire's original decision' (Gollapudi, 2021). One of the former cricketers, Sachin Tendulker, says, 'I am not convinced with the DRS rule at all...the tracking system is not full proof. It is not 100 percent correct', and it is 'unfair' for the players (Tendulkar, 2020). 


\section{Soft signal: a debate}

Soft signal refers to 'the visual communication by the bowler's end umpire to the third umpire (accompanied by additional information via two-way radio where necessary) of his/her initial on-field decision prior to initiating an Umpire Review' (ICC. 2021a). In 2016, ICC came up with this human intervention which is known as 'soft signal.' According to this rule, 'if despite the available technology, the third umpire is unable to decide with a high degree of confidence whether the original on-field decision should be changed, then he or she shall report that the replays are 'inconclusive', and that the on-field decision shall stand. The third umpire shall not give answers conveying likelihoods or probabilities' (ICC, 2017). Hence, one point is clear from this: the current umpiring technology is 'inconclusive' at times.

Humanizing the umpiring process through 'soft signal' is plausible, but it has already attracted a debate in the cricketing world which needs to be addressed accordingly. On the one hand, Simon Taufel, who was declared Umpire of the Year for 5 times between 2005 and 2008, regards 'soft signal' as the best way to rule on catches. On the other hand, former players like Shane Warne are against the 'soft signal' and appeal that the 'soft signal' from the on-field umpires should be eliminated in cricket (Pierik, 2018). Likewise, a former Indian Test and ODI men's team captain was furious about the soft signal and said, 'Why can't we have 'I don't know' soft signal for the umpire?'. In addition to this, there are players such as Stuart Broad and administrator VVS Laxman, who oppose soft signals used by third umpires. A broadcaster named Michael Atherton calls soft signal a 'nonsense' as the TV umpire remains unconvinced about the catch but must stick with 'out' signal (Gollapudi et al., 2021). From all these critical reflections, rethinking about 'soft signal' is required if the umpiring technology is expected to be used for a fair competition in cricket.

\section{Sledging and stump mics}

Sledging has been reported as an ethical issues of cricket. Sledging is described as; 'aggressive actions and verbal interactions with the aim of disrupting concentration and altering the emotional states of opponents' (Davis et al., 2018). Cricketers do use sledging to gain competitive advantage in the game (Fraser, 2003; Dixon, 2007; Joseph \& Cramer, 2011; Hancock, 2013; Davis et al., 2018). To tackle this issue umpires and broadcasters oversee on-field players' communications through cameras and stump mics. The record has already shown that in the last five years more than forty percent of total code of conduct breaches in men's cricket were related to sledging against opponents, own teammates, own fate or play, umpires, and fans (ICC, 2021b; Middleton, 2021).

However, ICC's approach to oversee players communication through stump mics is understandable but allowing home broadcasters to broadcast such communications is not justifiable in many ways. One of the retired cricket players, Michael Holding, argues that the on-field verbal communication - sledging-has been traded as a 'product' by using stump mics (SuperSport, 2019). Sledging that is backed up by rivalries is always a major interest for the audiences. First, Holding's argument warns the idea of commercializing sledging. Second, how would it impact if 'abusive' communications or on-field 'obscenities' are consumed by the vulnerable group? Third, 
some cricketers have indicated the risk of manipulating the on-field verbal exchanges by broadcasting selective portions of the onfield communication by the home boards or broadcasters (Bal, 2019). Fourth, when such 'illicit' contents are published in public, it automatically defames the game itself which is contrary to 'The Spirit of Cricket.' But the ICC has been defending its position by stating that its actions are set to check on-field abusive verbal exchanges among players and to involve fans with the activities that go in the middle of the playground. On top of that, the responsibility of maintaining 'Spirit of Cricket' widely relies on captains, players, and match officials (ICC, 2019a). It widely excludes the responsible stakeholders such as governing bodies and media.

Hence, ICC needs to be cautious about publicizing 'unacceptable' on-field communications in the name of 'regulating' adverse on-field conducts from the players and support personnel because it has already posed a multi-dimensional threat to its stakeholders. If stump mics are used to set an example on how to act or not to act on-field for the players in lower level of cricket, there might be other creative and inspiring methods to educate them.

\section{Technological inequality}

ICC (2021a) has formulated minimum technological requirements for the home board of applying DRS in an international match, but not all home cricketing boards can afford such type of full-fledged technological installments on the playing ground. Consequently, ICC (2021a) has mandated thatDRS 'shall notapply for matches between a Full Member country and Associate Member countries (whose matches have been granted T20I status) and for matches between such Associate Member countries.' So, 'it is unlikely to be seen in all matches, given that the poorer boards are unable to afford their share of the cost for the full DRS... due to the cost burden on the home board of providing the systems in conjunction with the host broadcaster' (McGlashan, 2015). From this, the governing body itself has systematically created a technological hierarchy among cricketing nations. In addition to this, application of umpiring technology has been prioritizing able-bodied men's elite level cricket excluding women's and differently abled cricket.

To address such issues, McGlashan (2015) suggests ICC to bear all the costs related to DRS in the international matches to meet the equal access requirement. If it is implemented through ICC in all the cricketing nations regardless of gender, physical or mental ability, every cricketing nation or stakeholder can be ensured of equal access to the umpiring technologies.

\section{Conclusion}

This study was determined to conceptualize $\mathrm{AI}$ and reflect the ethical considerations of applying umpiring technology in the game of cricket. The study of the concept of AI shows that modern technology has an evolving nature, and currently available technology has not reached its promises yet to be declared as 'intelligent.' (McCarthy, 2004; Haenlein \& Kaplan, 2019). Therefore, umpiring technology in cricket is also evolving (Krishna, 2021) and remains 'ambiguous' at times (ICC, 2017; Loland, 2018). Meanwhile, applying such technologies in umpiring might not stay away from the discrepancies or debates which brings in several ethical challenges which have been discussed in this paper earlier. These ethical challenges affect multiple stakeholders 
including players, officials, administrators, broadcasters, and fans. Moreover, it has also influenced the integrity of sport. Having said this, this research does not undermine the positive impacts of modern technology in global sports. However, we cannot neglect the technological and ethical issues that may arise in the future. Being limited to ethical considerations of umpiring technology, this study lacks the study of several dimensions such as privacy of the on-field communication among players, dignity of players and umpires, and sports governance related to technological implementation.

Nevertheless, there is a possibility that the umpiring technology can improve in the long run. To address such types of multi-dimensional ethical issues, a holistic approach needs to be developed, applied, and evaluated iteratively. A redesigned integrated approach to combine human and technology can be developed for the better umpiring technology because 'integrated approach prevails human dignity or existence' of all the stakeholders involved and affected from it (Collins, 2019). The international governing body such as ICC can lead more academic and non-academic discussions on the 'grey areas' such as 'soft signal' and 'umpire's call' for the required improvisations based on the discussions and research held among all the stakeholders. Before engaging in multi-dimensional discussions, stakeholders need to understand and acknowledge the fundamental and ethical issues of AI that are applied as umpiring technology in cricket. Such types of discussions can become more engaging if the discussions include the views from multiple stakeholders to make the approach more inclusive and to promote more involvement of multiple parties in decision or policy making before engaging in any type of improvements related to the issues. If all the stakeholders go hand in hand, the ethical challenges of umpiring technology in cricket can be addressed in a better way than before.

\section{References}

Bhattacharya, R. (2011, February 26). The match referee and third umpire. ESPNCricinfo. https://www.espncricinfo.com/story/crickets-turning-points-the-match-referee-and-thirdumpire-499652

Collins, H. (2019). Applying Philosophy to Refereeing and Umpiring Technology. Philosophies (Basel), 4(2), 21-0.

Davis, P.A, Davis, L, Wills, S, Appleby, R, \& Nieuwenhuys, A. (2018). Exploring "Sledging" and interpersonal emotionregulation strategies in professional cricket. The Sport Psychologist, 32(2), 136-145.

Dixon, N. (2007). Trash talking, respect for opponents and good competition. Sport, Ethics and Philosophy, 1(1), 96-106.

Dobell, G. (2021, May 14). ICC consider expanding T20 World Cup to 20 teams. ESPNCricinfo. https://www.espncricinfo. $\mathrm{com} /$ story/icc-consider-expanding-t20-worldcup-to-20-teams-1263075

ESPNCricinfo. (2021, November 30). Abid Ali, Shaheen Shah Afridi lead the way as Pakistan go 1-0 up. ESPNCricinfo. https:// www.espncricinfo.com/series/pakistan-inbangladesh-2021-22-1277971/bangladesh-vspakistan-1st-test-1277977/full-scorecard

Fraser, D. (2003). Cricket and the law: The man in white is always right. ProQuest Ebook Central https://ebookcentral.proquest.com 
Gollapudi, N. (2021, March 22). Virat Kohli: 'Umpire's call right now is creating lots of confusion.' ESPNCricinfo. https://www. espncricinfo.com/story/ind-vs-eng-2020-211st-odi-virat-kohli-umpire-s-call-right-nowis-creating-a-lot-of-confusion-1256275

Gollapudi, N., Roller, M. \& Shetty, V. (2021, March 18). Virat Kohli: 'Why can't we have'I don't know' soft signal for the umpire?' ESPNCricinfo. https://www.espncricinfo. com/story/ind-vs-eng-2020-21-4th-t20i-viratkohli-why-can-t-we-have-an-i-don-t-knowsoft-signal-for-the-umpire-1255186

Haenlein, M., \& Kaplan, A. (2019). A brief history of artificial intelligence: On the past, present, and future of artificial intelligence. California Management Review, 61(4), 5-14. DOI 10.1177/0008125619864925.

Hancock, N. (2013, November 26). It's time for cricket to clean up its sledging excesses. The Conversation. https://theconversation.com/ its-time-for-cricket-to-clean-up-its-Sledgingexcesses-20736

Hawk-Eye Innovation. (2011). Official Response to questions posed on Tendulkar LBW. https://resources.platform.pulselive.com/ test/HawkEye/document/2015/08/27/ c94e3cc6-f8d9-4e5b-8bc1-8f4f795f9948/ Official_Response_to_questions_posed_on Tendulkar_LBW.pdf

Hawk-Eye Innovation. (2015). Ultraedge. https:// www.hawkeyeinnovations.com/products/balltracking/cricket-decision-review-system

Hyde, D. (1997). From heaps and gaps to heaps of gluts. Mind, 106(424), 641+. https://link.gale.com/apps/doc/A20035454/
Lit R C ? u= leuven \& s id=bookmark LitRC\&xid $=72092675$

International Cricket Council. (2017). ICC Men's Test Match Playing Conditions.https:// pulse-static-files.s3.amazonaws.com/ICC/ document/2017/10/05/226f919d-1bdd4719-a32b-11b582a1c8a0/ICC-Men-s-TestMatch-Playing-Conditions-2017-CodeFINAL-051017.pdf

International Cricket Council. (2019a). Code of conduct for players and player support personnel. https://iccstatic-files.s3 . amazonaws.com/ICC/ document/2019/07/31/956d33de-e9aa40c6-b62b-3 fa3cc6bf3bd/Code-of-Conductfor-Players-and-PSP-FV-effective-1August-2019-.pdf

International Cricket Council. (2019, November 19b). The Three Formats of Cricket. https:// www.icc-cricket.com/about/cricket/gameformats/the-three-formats

International Cricket Council. (2020a). Interim playing regulations. https:// resources.pulse.icc-cricket.com/ICC/ document/2020/07/08/06782a96-fab24b34-afb4-ec82ab1 ef5de/FAQs-on-interimregulations.pdf

International Cricket Council. (2020, November 17b). What is cricket? -Umpire roles.. https:// www.icc-cricket.com/video/310670

International Cricket Council. (2021a). ICC Men's Twenty20 Internationals playing conditions. https://resources.pulse.icc-cricket.com/ICC/ document/2021/07/05/874a426e-fe06-4415- 
b0f5-5148a4aa0ef8/ICC-Playing-Conditions05-Men-s-Twenty20-International-May-2021. pdf

International Cricket Council. (2021b). ICC Code of Conduct Breaches and Penalties. https:// www.icc-cricket.com/about/cricket/rules-andregulations/code-of-conduct\#: : :text=The $\% 20$ ICC $\% 20$ Code $\% 20$ of $\% 20$ Conduct, the $\% 20$ 'spirit $\% 20$ of $\% 20$ cricket' $\% 3 \mathrm{~B}$

Joseph, S. \& Cramer, D. (2011). Sledging in Cricket: Elite English Batsmen's Experiences of Verbal Gamesship. Journal of Clinical Sport Psychology, 5(3), 237-251.

Kamble, P.R., Keskar, A.G. \& Bhurchandi, K.M. (2019). Ball tracking in sports: a survey. Artif Intell Rev 52, 1655-1705. https://doi. org/10.1007/s10462-017-9582-2

Krishna, S. A. (2021, March 28). Cricket: Is Indian captain Virat Kohli disrespecting umpires? GulfNews.https://gulfnews.com/sport/cricket/ icc/cricket-is-indian-captain-virat-kohlidisrespecting-umpires-1.1616923767134

Loland, S. (2018). Ethics of Technology in Sport. In Ethics in Sport (pp. 273-286). Champaign, IL: Human Kinetics.

MacFarlane, A. (2013). Information, knowledge and intelligence. Philosophy Now. https:// philosophynow.org/issues/98/Information Knowledge_and_Intelligence

McCarthy,J.(2004,November24). Whatisartificial intelligence? https://borghese.di.unimi.it/ Teaching/AdvancedIntelligentSystems/ Old/IntelligentSystems_2008_2009/Old/ IntelligentSystems_2005_2006/Documents/ Symbolic/04_McCarthy_whatisai.pdf

McGlashan, A. (2015, October 19). Ultra-edge ready for Test use. ESPNCrickinfo. https:// www.espncricinfo.com/story/ultra-edgeready-for-test-use-930623
Middleton, D. (2021, December 11). England given heavy penalty for slow over rate. Cricket Australia. https://www.cricket.com.au/news/ england-penalised-slow-over-rates-gabbatest-ashes-australia-world-test-championshipjoe-root/2021-12-11

Mittelstadt, B. D., Allo, P., Taddeo, M., Wachter, S., \& Floridi, L. (2016). The ethics of algorithms: Mapping the debate. Big Data \& Society, 3(2), 2053951716679679.

Pierik, J. (2018, December 17). Soft signal best way to rule on catches: Taufel. The Sunday Morning Herald. https://www.smh.com.au/ sport/cricket/soft-signal-best-way-to-rule-oncatches-taufel-20181217-p50mp8.html

Rhodes, L. (Producer) \& Orlowsky, J. (Director). (2020). The social dilemma [Video File]. https:/www.netflix.com/np/title/81254224

Schneider, M. (Producer) \& Popp, C. (Director). (2020, April 17). Explained | Cricket [Video file]. Retrieved from https://www.youtube. $\operatorname{com} /$ watch? $\mathrm{v}=\mathrm{NZGLHdcw} 2 \mathrm{RM}$

Selvey, M. (2007, December 18). Rows over replays should put technology's flaws into focus. The Guardian. https://www. theguardian.com/sport/2007/dec/18/cricket. englandcricketseries 1

SuperSport. (2019, January 10). Crossing the Line [Video file]. Retrieved from https://www. youtube.com/watch?v=MKcvHAec6GM

Tendulkar, S. [@sachin_rt]. (2020, December 28). The DRS has been brought in for a reason by @ICC \& if we are trusting the DRS then the reliance on it has to be 100\% [Tweet]. Twitter. https://twitter.com/ sachin_rt/status/1343519250699456513?ref_ $\mathrm{s} \mathrm{rc}=\mathrm{tw} \mathrm{src} \% 5 \mathrm{Et} \mathrm{fw} \% 7 \mathrm{Ctw}$ c a m p \% 5 Etweeembed\%7Ctwterm\%5E13437413325 $31990528 \% 7 \mathrm{Ctwgr} \% 5 \mathrm{E} \% 7 \mathrm{Ctwcon} \% 5 \mathrm{Es} 3$ \&ref_url=https $\% 3 \mathrm{~A} \% 2 \mathrm{~F} \% 2 \mathrm{Fwisden} . \operatorname{com} \%$ 
2 Fseries-stories $\% 2$ Faustralia-india $\%$ 2Fcontentious-umpires-call-saves-starcraises-a-furore

The Ethics Center. (2020, April 15). What is the difference between Ethics, Morality and the Law? [Video file]. Retrieved from https://www.youtube.com/ watch $\mathrm{v}=\mathrm{Xki} 2 \mathrm{fRA} 0 \mathrm{~b} Y 8 \& \mathrm{t}=235 \mathrm{~s}$

Watson, D. (2019). The Rhetoric and Reality of Anthropomorphism in Artificial Intelligence. Minds and Machines (Dordrecht), 29(3), 417440 .

Wisden. (2021, November 3). 'Tired Call Mr. Ump' - Jadeja's remarkable running catch controversially overturned by third umpire. Wisden.com. https://wisden.com/seriesstories/t20-world-cup-2021/tired-call-mrump-jadejas-remarkable-running-catchcontroversially-overturned-by-third-umpire
Zumhagen-Yekplé, K. (2016). Modernist Fiction and Vagueness: Philosophy, Form, and Language. Woolf Studies Annual, 22, 160164. https://wisden.com/series-stories/t20world-cup-2021/tired-call-mr-ump-jadejasremarkable-running-catch-controversiallyoverturned-by-third-umpire 